\title{
El contador público: formado desde la ética y la responsabilidad social empresarial
}

\author{
Leidy Yazmin García Suaza'; Luisa Fernanda Trujillo Gómez²; \\ Diego Fernando Urrea López ${ }^{3}$
}

RESUMEN $\mid$ El Contador Público de hoy es un profesional integral, que en el desarrollo de sus funciones llega a convertirse en un experto conocedor de la empresa, y es precisamente este nivel de comprensión el que lo habilita para el análisis y discernimiento que demandan los diferentes contextos y requerimientos de las empresas. Por consiguiente, la educación y la formación del Contador Público debe ser estudiada y analizada, con el fin de generar críticas constructivas desde una perspectiva de Responsabilidad Social Empresarial y Ética, como actor principal dentro de una sociedad, la cual le transfiere facultades especiales para dar fe de lo que presentan las organizaciones a sus grupos de interés.

El Contador Público debe representar en todos sus ámbitos una formación íntegra, fomentando acciones en pro de la comunidad y generando en cada uno de sus actos profesionales, sociales y familiares, un impacto positivo y altruista.

Responsabilidad Social Empresarial;

PALABRAS

Educación;

CLAVE

Formación;

Ética;

Organizaciones.

1 Estudiante de IX semestre de Contaduría Pública de la Fundación Universitaria del Área Andina: Igarcía208@ estudiantes.areandina.edu.co

2 Estudiante de IX semestre de Contaduría Pública de la Fundación Universitaria del Área Andina: @ estudiantes.areandina.edu.co

3 Docente del Programa de Contaduría Pública de la Fundación Universitaria del Área Andina: durrea@areanina.edu.co 


\section{The public accountant: formed from the ethics and corporate social responsibility}

\begin{tabular}{l|l} 
ABSTRACT & $\begin{array}{l}\text { The Public Accountant of today is an integral professional, that through the } \\
\text { development of his functions becomes an expert of the company, and it is } \\
\text { precisely this level of understandment that enables him tor the analysis and } \\
\text { discernment that different contexts demand and the business requires. }\end{array}$
\end{tabular}

Therefore, the education and training of the Public Accountant must be studied and analyzed in order to generate constructive criticism from the perspective of a Corporate Social Responsibility, being this a main actor within a society which has given him special powers to give faith of what organizations will present to their stakeholders.

The accountant must represent in all its fields the integral formation, promoting actions in favor of the community and generating in each one of his professional, social and family acts a positive and altruistic impact.

\section{Corporate Social Responsibility;}

Education;

KEYWORDS Training;

Ethics;

Organizations. 


\section{INTRODUCCIÓN}

La responsabilidad que el Estado colombiano ha otorgado a los contadores públicos, hace que su educación y formación sea cada vez más competente e íntegra, ya que su trabajo se ve enmarcado en situaciones de riesgos que por efecto de las presiones, los problemas fiscales de las empresas, el flujo de dinero ilegal, los estados financieros sin sustentaciones físicas o razonables entre otras situaciones, han puesto en tela de juicio la profesión contable, generando así una discrepancia entre los empresarios y los mismos entes de control de la Profesión.

Por lo anterior, se hace necesario desarrollar un ejercicio investigativo que evidencie la importancia del Contador Público con su Responsabilidad Social Empresarial, enmarcada desde la formación y educación de los nuevos profesionales de la Contaduría Pública, en la ciudad de Pereira.

Los cambios que la profesión de la Contaduría Pública ha tenido en los últimos años, frente al nuevo marco contable de las Normas Internacionales de Información Financiera y las reformas fiscales, han hecho que los nuevos profesionales de la contabilidad cambien su visión y se centren en lo relevante que tiene la profesión desde la toma de decisiones y la adecuada asesoría organizacional. Por tal razón, es importante conocer si el nuevo profesional de la Contaduría Pública reconoce la importancia que tiene frente a la sociedad, siendo este uno de los actores relevantes, dando fe pública de lo que realmente las organizaciones presentan en sus informes financieros como no financieros.

Por otra parte, es importante indagar que las universidades donde se encuentran ofreciendo el programa de Contaduría Pública, generen espacios de conciencia entre los estudiantes y fomenten la importancia de la Responsabilidad Social Empresarial como aporte al mejoramiento organizacional, impactando a la sociedad con sus buenas acciones como profesional íntegro, que le permita discernir actos de corrupción, tomando decisiones asertivas en pro de la ética y de la responsabilidad que tiene, como actor activo en los procesos económicos del país.

El Contador Público tiene como respaldo el Código de Ética, el cual se encuentra inmerso en la ley 43 de 1990 y emite unos principios que fortalecen la profesión, la hace más selectiva y genera una serie de responsabilidades frente a la sociedad; por consiguiente, es necesario retomarlos y hacerlos parte de cada una de las acciones que pueda generar en sus ámbitos profesionales, laborales, sociales y familiares.

Los 10 Principios Éticos Del Contador Público ley 431990

1. Integridad

2. Objetividad

3. Independencia

4. Responsabilidad 


\section{Confidencialidad}

6. Observaciones de las disposiciones normativas

7. Competencia y actuación profesional

8. Difusión y colaboración

9. Respeto entre colegas

Y es en la formación del Contador Público donde se puede fomentar la Ética y la Responsabilidad Social Empresarial; por consiguiente, es necesario hacer una revisión de los pensum y de las actividades cotidianas que tienen las universidades, para fomentar conciencia de la relevancia que tiene la Ética y la Responsabilidad Social, y así generar un estudio y un análisis comparativo frente a los principios éticos que el profesional de la contaduría debe interiorizar y colocar en práctica con sus actuaciones.

\section{METODOLOGIÍA}

La investigación será cualitativa y cuantitativa, lo que deduce que existirá un acercamiento a los principales actores del proceso de formación de los nuevos profesionales de la Contaduría Pública como los docentes, directivos y por supuesto los estudiantes de últimos semestres de las universidades de la ciudad de Pereira.

Teniendo como base este escenario, los investigadores tiene un papel primordial, ya que son ellos los que pueden tener la mejor información con un gran nivel estadístico de confiabilidad. El objetivo es determinar las diferentes acciones formativas del grupo de estudio, lo cual hace que se generen una serie de variables o categorías que luego serán objetos de estudio.

\section{MATERIALES Y MÉTODOS}

Tipo de estudio: inductivo es una manera de argumentación, frente al ordenamiento y análisis de un problema determinado de investigación. Este ejercicio utilizará particularidades de la población de estudio, generando categorías y variables propias de un contexto especifico y con base a ello, se generarán unos resultados comparativos y se podrá llegar a unas conclusiones y recomendaciones de lo especifico a lo general, en la formación de los nuevos profesionales desde la perspectiva de educación de Responsabilidad Social y de Ética.

\section{RESULTADOS ESPERADOS}

$\mathrm{Al}$ inicio de esta investigación se pretenden identificar las acciones pertinentes que se encuentran aplicando las universidades en la ciudad de Pereira, y así poder determinar 
la formación que el nuevo Contador Público está recibiendo desde la perspectiva de Responsabilidad Social Empresarial y de la Ética.

Se espera hacer una descripción de cada una de las actuaciones de los programas desde el pensum y sus actividades pedagógicas dentro y fuera del aula, como principales espacios para fomentar en los estudiantes este sentido de Responsabilidad Social Empresarial, y finalmente, generar unos espacios académicos donde se puedan dar a conocer las actuaciones de las Instituciones de Educación Superior, las cuales se centran en la formación y educación de los estudiantes del programa de Contaduría Pública en la ciudad de Pereira.

\section{IMPACTOS}

Impacto social. Generar cambios significativos en los planes de educación y formación de la profesión contable, fomentado la reflexión crítica de la responsabilidad social, ambiental y económica que el contador Público tiene frente a la sociedad, fomentando así unas mejores prácticas en las organizaciones y generando nuevas acciones que ayuden a impactar a la sociedad en diferentes ámbitos.

Además de ello, la ética como característica principal de las acciones emitidas por el profesional de la Contaduría Pública, frente a un sinnúmero de situaciones que posee como actor de toma de decisiones de las organizaciones, hará que se visualice una perspectiva diferente del contador actual, dando mayor credibilidad del nuevo profesional de Contaduría Pública frente a la sociedad. Además, hará que la profesión del Contador Público sea vista desde nuevas perspectivas, con una visión más filantrópica y menos financiera y contable.

Impacto económico. El nuevo profesional de la contaduría a través de la formación en Responsabilidad Social Empresarial y Ética desarrollará nuevas visiones empresariales, las cuales ayudarán a la organización en diferentes áreas significativas, manejando adecuadamente las transacciones económicas, permitiendo que su desarrollo sostenible permanezca en óptimas condiciones.

Esto admitirá que el profesional contable tenga poder de decisión frente a ciertos manejos organizacionales, los cuales le permitirán actuar de manera más responsable y ética. 
2. Comisión, D. É. (2018). Código de ética profesional.

3. Zamorano, G. E. (2017). Desarrollo ético de los profesionales de la contaduría y la administración.

4. Responsabilidad social empresarial: Decisiones, reflexiones y casos de estudio (2017) Barranquilla: Universidad del Norte; 2017.

5. Nieto-Morales, C., \& Solange, D. M. M. (2018). Trabajo social en el siglo XXI: Desafíos para la formación académica y profesional.

6. Guevara, J. A., Yidalcy, G. D., \& González, M. D. (2009). Alcance y contribución del profesional contable para el crecimiento de la sociedad 